\title{
Performance prediction of Darrieus vertical axis wind turbines using double multiple stream-tube model
}

- Le Thi Hong Hieu

- Nguyen Chi Cong

- Luong Huu Trong

Ho Chi Minh city University of Technology, VNU-HCM

(Manuscript Received on July 08 ${ }^{\text {th }}$, 2013, Manuscript Revised September 03 ${ }^{\text {rd }}$, 2013)

\section{ABSTRACT}

Horizontal and vertical axis wind turbines (HAWTs and VAWTs) are two main kinds of wind turbines, which are the most popular way to catch energy from the wind. By comparison, VAWTs have some advantages, but they also have the complexity in aerodynamics that needs a deep investigation. A code is developed based on
Double multiple stream-tube and corrections of the dynamic stall for Darrieus VAWTs. It is capable of estimating the output power versus different operating conditions defined by the tipspeed-ratio. The code is also validated with experimental data of many SANDIA Darrieus VAWT turbines.

Key words: DMST, VAWT, HK-VAWT, Darrieus type, momentum theory, blade element method, Dynamic stall, SANDIA 17-m, SANDIA 5-m.

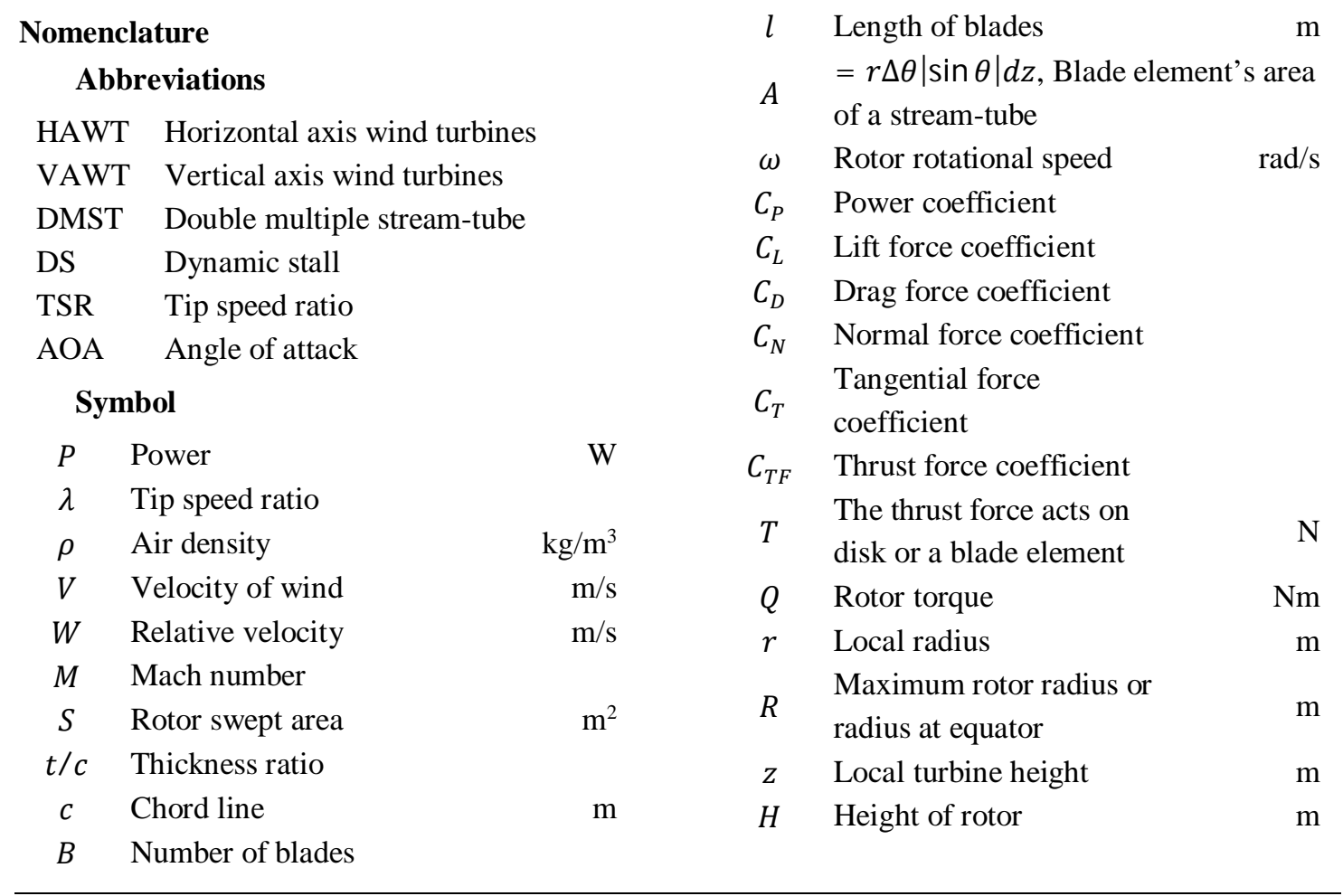




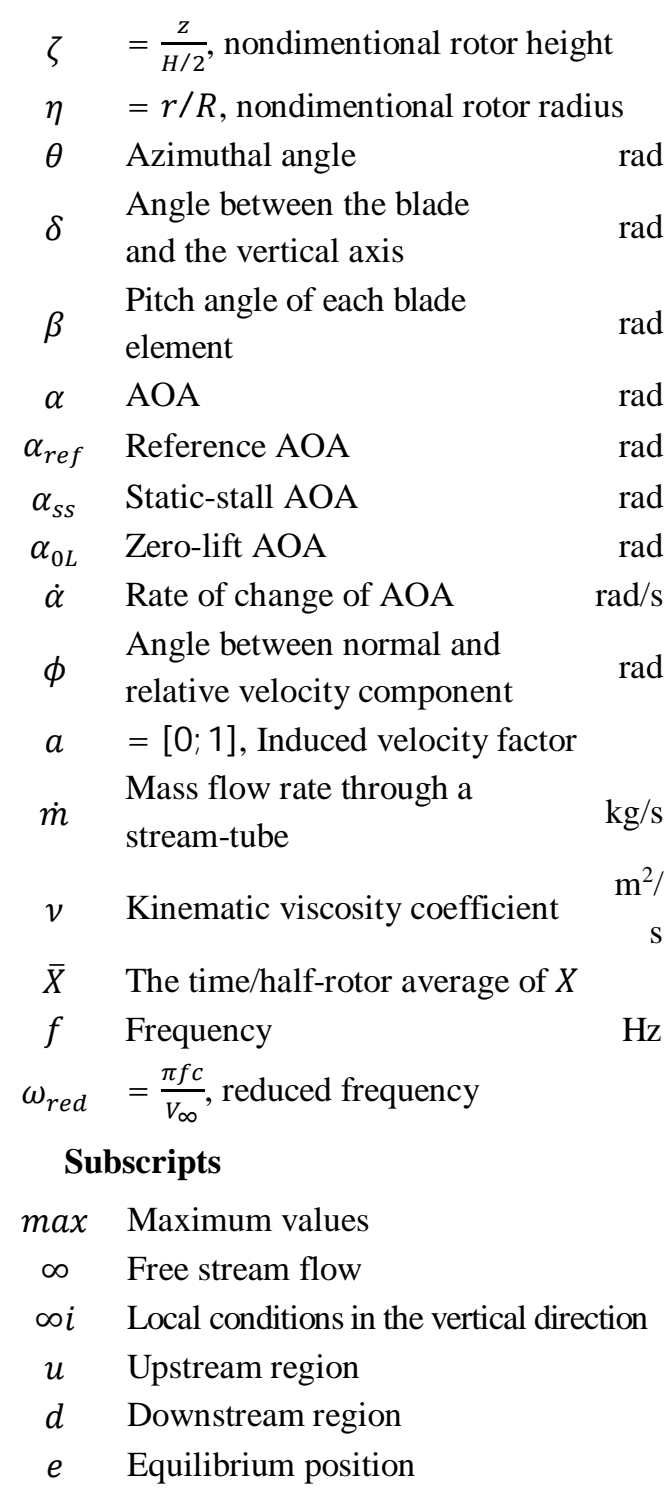

\section{INTRODUCTION}

Modern wind turbines are the primary devices to convert the wind's momentum into rotor rotation thanks to a number of blades. In addition, they can be classified into two main categories according to their axis alignment: horizontal axis wind turbines (HAWTs) and vertical axis wind turbines (VAWTs). While HAWTs are more popular in large scale thanks to their economical efficiency, VAWTs are commonly applied in small and medium power range. However, VAWTs have many special advantages such as working independent of wind direction, ease of manufacture and maintenance and making less noise... On the other hand, VAWTs also have their disadvantages, for example, self-starting and complex aerodynamics; therefore, they need further researches. Tip-speed-ratio, an important variable of wind turbine, is the ratio between the tangential speed of the tip of a blade and the actual velocity of the wind:

$$
T S R=\lambda=\frac{R \omega}{V_{\infty}}
$$

Double multiple stream-tube model (DMST) is a well-known analysis method for VAWTs and developed by Paraschivoiu [1] in order to simulate the flow through VAWT. The model, which is the combination of momentum theory and blade element method, is a simple and efficient way to predict the output power of VAWTs quickly, compared to experimental and other numerical simulation methods. Paraschivoiu validated his results by many experimental and CFD results, presented in [2]. DMST model gives a good agreement with VAWTs' performance, especially in low and medium TSR range when integrated with some correction models of unsteady effect, for instance, dynamic stall, stream-tube expansion, tip loss...

Betz [ 3 ] estimated the maximum power that can be got from the wind kinetic energy by using a simplified method for HAWT where the turbine is replaced by a circular actuator disc. According to Betz, the maximum "ideal power coefficient" that a HAWT can be received is 0.5926 and called the Betz limit.

$$
C_{P}=\frac{P_{\max }}{\frac{1}{2} \rho V_{\infty}^{2} S}=\frac{16}{27}=0.5926
$$

The model, even this limit, cannot be applied for VAWT; however, it is possible to develop another comparable method to simulate the flow through turbine by dividing the turbine

\section{Trang 54}


into many stream-tube. This work focuses on using DMST model and Dynamic Stall model to predict output power of VAWTs. The results are validated with some experimental data of existing VAWTs.

\section{DOUBLE MULTIPLE STREAM-TUBE MODEL}

The idea of DMST model is the equilibrium of thrust forces act on a piece of the blade which calculated by momentum theory and blade element method. Considering a VAWT with curve blades, the rotor has the height $H$, maximum radius $R$, as shown in Figure 1. This analytical method divides the rotor into two parts: one for the upstream half-cycle and the other for the downstream half-cycle, which contains many layers, and each layer has many stream-tubes. The induced factors through the rotor are calculated and based on the principle of the twoactuator disks in tandem at each stream-tube.

The following analysis is applied for a single stream-tube and assuming that the wind velocity profile is uniform $\left(\boldsymbol{V}_{\infty \boldsymbol{i}}=\boldsymbol{V}_{\infty}, \forall \boldsymbol{i}\right)$.

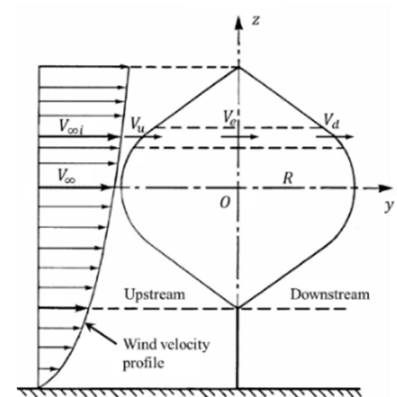

Front view

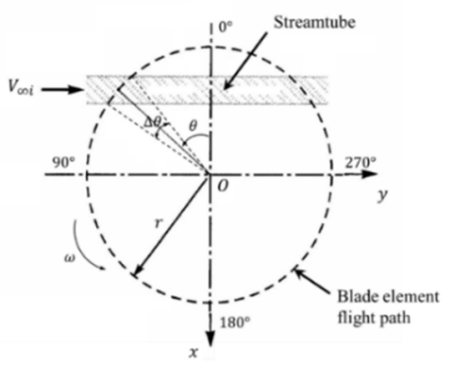

Plan view
According to linear momentum theory, the relationships between the velocities through a stream-tube are

$$
\begin{gathered}
V_{u}=\left(1-a_{u}\right) V_{\infty} \\
V_{e}=\left(1-2 a_{u}\right) V_{\infty} \\
V_{d}=\left(1-a_{d}\right) V_{e}=\left(1-a_{d}\right)\left(1-2 a_{u}\right) V_{\infty}
\end{gathered}
$$

The axial thrust force on the disk is

$$
\begin{aligned}
T_{u, d_{1}} & =\dot{m}\left(V_{\infty, e}-V_{e, e^{\prime}}\right) \\
& =\frac{1}{2} \rho_{\infty} V_{\infty, e}^{2}(r \Delta \theta|\sin \theta| d z) \times\left(4 a _ { u , d } \left(1-a_{u, d} .\right.\right. \\
& =\frac{1}{2} \rho_{\infty} V_{\infty, e}^{2} A \times\left(4 a_{u, d}\left(1-a_{u, d}\right)\right)
\end{aligned}
$$

Moreover, its coefficient:

$$
C_{T F_{u, d_{1}}}=4 a_{u, d}\left(1-a_{u, d}\right)
$$

However, based on experimental data, the suggestion for VAWTs' axial thrust force can be expressed as equation (8) [4]. The second term in equation (8) (for $\boldsymbol{a}>\mathbf{1} / \mathbf{3}$ ) can be used for a whole range of induced velocity factors.

$$
C_{T F_{u, d_{1}}}=\left[\begin{array}{cc}
4 a(1-a) & \text { for } a \leq 1 / 3 \\
4 a\left(1-\frac{1}{4} a(5-3 a)\right) & \text { for } a>1 / 3
\end{array}\right.
$$

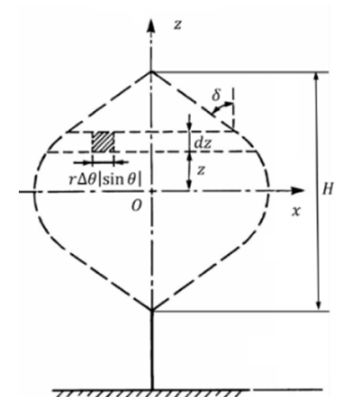

Side view

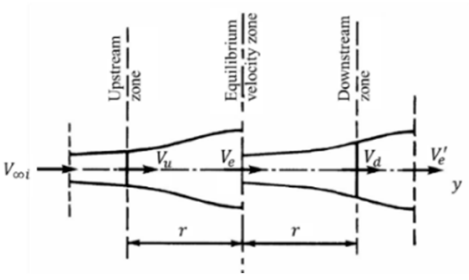

Stream-tube velocity component

Figure 1. Definition of rotor geometry of Darrieus VAWT of DMST model (edited from [1]) 


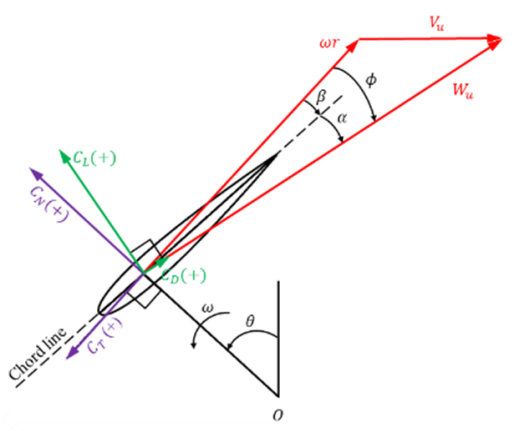

Figure 2. Angles, force vectors and velocity vectors for a blade element in upstream region

The blade element method is also used to determine the axial thrust force caused by aerodynamic forces. Figure 2 indicates angles, velocity components and positive direction of forces for one-blade element in the upstream zone.

The relative velocity can be obtained from the axial and the normal velocity components as follow

$$
\begin{aligned}
& W_{u, d} \\
& =\sqrt{\left(V_{u, d} \cos \delta \sin \theta\right)^{2}+\left(\omega r+V_{u, d} \cos \delta \cos \theta\right)^{2}}
\end{aligned}
$$

The local Reynolds number:

$$
R e_{u, d}=\frac{W_{u, d} c}{v}
$$

The angle between normal and relative velocity components is $\boldsymbol{\phi}$ of which magnitude is

$$
|\phi|=\cos ^{-1}\left(\frac{\left(V_{u, d} \cos \delta\right)^{2}-W_{u, d}^{2}-(\omega r)^{2}}{-2 W_{u, d} \times \omega r}\right)
$$

Angle of attack $\boldsymbol{\alpha}$ can be expressed as

$$
\alpha=\left[\begin{array}{c}
\alpha_{u}=-|\phi|+\beta \\
\alpha_{d}=|\phi|+\beta
\end{array}\right.
$$

Lift coefficient $\boldsymbol{C}_{\boldsymbol{L}}$ and drag coefficient $\boldsymbol{C}_{\boldsymbol{D}}$ can be interpolated from the aerodynamic characteristic of airfoil used, which depend on $\boldsymbol{R} \boldsymbol{e}_{\boldsymbol{u}, \boldsymbol{d}}$ and $\boldsymbol{\alpha}_{\boldsymbol{u}, \boldsymbol{d}}$. The normal and tangential force coefficients are calculated as follows

$$
C_{N}=\left[\begin{array}{l}
C_{N_{u}}=C_{L_{u, d}} \cos |\phi|-C_{D_{u, d}} \sin |\phi| \\
C_{N_{d}}=C_{L_{u, d}} \cos |\phi|+C_{D_{u, d}} \sin |\phi|
\end{array}\right.
$$

$$
C_{T}=\left[\begin{array}{c}
C_{T_{u}}=-C_{L_{u, d}} \sin |\phi|-C_{D_{u, d}} \cos |\phi| \\
C_{T_{d}}=C_{L_{u, d}} \sin |\phi|-C_{D_{u, d}} \cos |\phi|
\end{array}\right.
$$

The time average thrust force acting on a blade element in a stream-tube is

$$
\begin{aligned}
\overline{T_{u, d_{2}}}=\frac{\Delta \theta B}{2 \pi} & \times \frac{1}{2} \rho_{\infty} W_{u, d}^{2} \times c \frac{d z}{\cos \delta} \\
& \times\left(-C_{N_{u, d}} \cos \delta \sin \theta-C_{T_{u, d}} \cos \theta\right)
\end{aligned}
$$

The thrust force in equations (6) and (15) must be equal, so

$$
\begin{aligned}
4 a(1- & \left.\frac{1}{4} a(5-3 a)\right)=\frac{B c}{2 \pi r} \times\left(\frac{W_{u, d}}{V_{\infty, e}}\right)^{2} \\
& \times\left(-\frac{C_{N_{u, d}} \sin \theta}{|\sin \theta|}-\frac{C_{T_{u, d}} \cos \theta}{|\sin \theta| \cos \delta}\right)
\end{aligned}
$$

Solving the above equation (16) to find the induced factor $\boldsymbol{a}$, and the tangential force coefficient $\boldsymbol{C}_{\boldsymbol{T}}$ of each blade element as well. These values are then integrated along the blade, the torque on a complete blade is a function of $\boldsymbol{\theta}$ :

$$
Q_{u, d}(\theta)=\frac{1}{2} \int_{-1}^{1} \rho_{\infty} W_{u, d}^{2} C_{T_{u, d}} r\left(c \frac{H / 2}{\cos \delta}\right) d \zeta
$$

The average torque of the rotor in the upstream region produced by half of $\boldsymbol{B}$ blades, given by:

$$
\overline{Q_{u}}=\frac{B}{2 \pi} \int_{0}^{\pi} C_{Q_{u}}(\theta) d \theta
$$

Moreover, its coefficient:

$$
\begin{aligned}
\overline{C_{Q_{u}}} & =\frac{\overline{Q_{u}}}{\frac{1}{2} \rho_{\infty} V_{\infty}^{2} S R} \\
& =\frac{B c H}{4 \pi S} \int_{0}^{\pi} \int_{-1}^{1}\left(\frac{W_{u}}{V_{\infty}}\right)^{2} C_{T_{u}} \frac{\eta}{\cos \delta} d \zeta d \theta
\end{aligned}
$$

Similarly, that of the rotor in the downstream region is

$$
\begin{aligned}
\overline{C_{Q_{d}}} & =\frac{\overline{Q_{d}}}{\frac{1}{2} \rho_{\infty} V_{\infty}^{2} S R} \\
& =\frac{B c H}{4 \pi S} \int_{\pi}^{2 \pi} \int_{-1}^{1}\left(\frac{W_{d}}{V_{\infty}}\right)^{2} C_{T_{d}} \frac{\eta}{\cos \delta} d \zeta d \theta
\end{aligned}
$$

The power coefficient of wind turbine is

$$
C_{P}=\lambda\left(\overline{C_{Q_{u}}}+\overline{C_{Q_{d}}}\right)
$$

\section{Trang 56}


The code, called HK-VAWT, is built in order to automate the calculating process to predict the power coefficient and export formatted data files, which allows to be plotted with Tecplot, particularly the power curve $\left(\boldsymbol{C}_{\boldsymbol{P}}\right.$ versus TSR). The inputs for analyzing are from wind turbine properties including:

- Airfoil data (airfoil type, data sets of lift and drag coefficients versus Reynolds number and AOA, thickness ratio $t / c$ )

- Rotor geometry (rotor shape, number of blades $B$, chord length $c$, heigh $H$ and maximum radius $R$ of rotor)

-Operation conditions (working wind velocity $V_{\infty}$ or rotor rotational speed $\omega$, air density $\rho$, kinematic viscosity coefficient $v$ )

DMST method needs the aerodynamic characteristics of airfoil section, which is used in VAWT turbines, in functioning of the large range of AOA and Reynolds number. As symmetrical airfoils are commonly used in VAWTs, HKVAWT utilizes the results of Robert and Paul [5] that provided experimental lift and drag coefficients of seven symmetrical airfoils with Reynolds number varying from $10^{4}$ to $5 \times 10^{6}$ and maximum AOA is up to $180^{\circ}$. In addition, some authors can use the coefficients, which are extra-interpolated from low AOA's data by theoretical models, for example, Viterna method. The Darrieus VAWTs were first developed with the Ideal troposkien rotor geometry. Later, it is modified to become four different shapes including Cantenary, Parabola, Sandia and Modified troposkien. These various rotor shapes were introduced by Paraschivoiu in form of equations and non-dimensional data sets with 40 layers [1].

At each layer defined by the $\mathrm{Z}$ plane, the rotor is divided into $\boldsymbol{N}$ double stream-tubes. Its azimuthal angle is defined by equation (33), and $N=21$ is used in this work.

$$
\theta_{j}=(j-0.5) \times \frac{\pi}{N} \text { with } j \in[1 ; 2 N]
$$

DMST provides a useful and immediate tool to predict VAWTs power coefficient. However, corrections should be applied to account for the unsteady aerodynamic behavior of flow around turbine blade. In the context of this research paper, the dynamic stall is considered.

\section{DYNAMIC STALL MODEL}

As mentioned above, VAWTs operation involves different unsteady and complex aerodynamic phenomena. Thus, the application of DMST model alone, which is based on steady assumption, is not sufficient to simulate the flow behaviour to provide accurate power coefficient. According to Paraschivoiu [1], there are two main correction models that should be applied for VAWTs with curve blades: dynamic stall and secondary effect [1]. Dynamic stall (DS) is a complex, unsteady phenomenon related to large and rapid variations of $\mathrm{AOA}$; furthermore, it effects on low tip speed ratio range. Under such conditions, the dynamic lift and drag characteristics present a hysteresis response; besides, the values of AOA at stall are completely different when the airfoil is in pitching movement with increasing or decreasing AOA. Moreover, they are not similar to the ones in static conditions.

Therefore, the aim of DS model is to propose a methodology for computing the dynamic characteristics from the available experimental static coefficient [1]. Gormont [6] defined a reference AOA that differs from geometrical AOA in equation (23):

$$
\alpha_{\text {ref }}=\alpha-K_{1} \Delta \alpha
$$

where

$$
\begin{aligned}
& K_{1}=\left[\begin{array}{cc}
1 & \text { when } \dot{\alpha} \geq 0 \\
-0.5 & \text { when } \dot{\alpha}<0
\end{array}\right. \\
& \Delta \alpha=\left[\begin{array}{cc}
\gamma_{1} S & \text { when } S \leq S_{c} \\
\gamma_{1} S_{c}+\gamma_{2}\left(S-S_{c}\right) & \text { when } S>S_{c}
\end{array}\right.
\end{aligned}
$$




$$
\begin{gathered}
S=\sqrt{\frac{c \dot{\alpha}}{2 W}} \\
S_{c}=0.06+1.5(0.06-t / c)
\end{gathered}
$$

Some parameters are presented in Error! Not a valid bookmark self-reference.

Finally, the dynamic coefficients are given by

$$
\begin{gathered}
C_{L}^{d y n}=C_{L}\left(\alpha_{0 L}\right)+m\left(\alpha-\alpha_{0 L}\right) \\
C_{D}^{d y n}=C_{D}\left(\alpha_{r e f}\right)
\end{gathered}
$$

\begin{tabular}{|c|c|c|}
\hline & For lift characteristic & For drag characteristic \\
\hline$M_{1}$ & $0.4+5(0.06-t / c)$ & 0.2 \\
\hline$M_{2}$ & $\begin{array}{l}0.9 \\
+2.5(0.06-t / c)\end{array}$ & $\begin{array}{l}0.7 \\
+2.5(0.06-t / c)\end{array}$ \\
\hline$\gamma_{m a}$ & $1.4-6(0.06-t / c)$ & $1-2.5(0.06-t / c)$ \\
\hline$\gamma_{2}$ & \multicolumn{2}{|c|}{$\gamma_{\max }=\max \left(0 ; \min \left(1 ; \frac{M-M_{2}}{M_{1}-M_{2}}\right)\right)$} \\
\hline$\gamma_{1}$ & $\gamma_{2} / 2$ & \begin{tabular}{|c|}
$\mathbf{0}$ \\
\end{tabular} \\
\hline
\end{tabular}

with

$m=\min \left(\frac{C_{L}\left(\alpha_{r e f}\right)-C_{L}\left(\alpha_{0 L}\right)}{\alpha_{r e f}-\alpha_{0 L}} ; \frac{C_{L}\left(\alpha_{s s}\right)-C_{L}\left(\alpha_{0 L}\right)}{\alpha_{s s}-\alpha_{0 L}}\right)$

Table 1. Parameters for Dynamic stall model

However, Gormont model was developed for helicopter blades, which its maximum AOA is lower than VAWTs', so it will over-predict the effects of DS on VAWTs' performance [6]. Berg and Masse [6] introduced a modified model to Gormont's dynamic coefficients as follow:

$$
\begin{aligned}
& C_{L, D}^{\text {mod }} \\
& =\left[\begin{array}{cl}
C_{L, D}\left(\alpha^{\prime}\right)+\frac{A_{M} \alpha_{S S}-\alpha^{\prime}}{A_{M} \alpha_{S S}-\alpha_{S S}}\left(C_{L, D}^{d y n}-C_{L, D}\left(\alpha^{\prime}\right)\right. & \alpha \leq A_{M} \alpha_{S S} \quad \text { (42) } \\
C_{L, D}\left(\alpha^{\prime}\right) & \alpha>A_{M} \alpha_{S S}
\end{array}\right.
\end{aligned}
$$

where $\boldsymbol{A}_{\boldsymbol{M}}$ is an empirical constant. Masse suggested that $\boldsymbol{A}_{\boldsymbol{M}}=\mathbf{1 . 8}$ while a value of six was suggested by Berg [6]. In our validation, it is found that the later gives a good agreement to SANDIA turbine's performance.

\section{RESULTS AND DISCUSSION}

Results from the current study on estimating power coefficient of VAWTs based on DMST are analyzed in two steps. Firstly, the DS model is verified to the experimental results with oscillating pitch angles on the NACA 4415 airfoil by Hoffmann et al. [7]. Secondly, HK-VAWT code is validated by experimental power coefficients of VAWT configurations showed in Table 2.

Figure 3 presents predicted and experimental lift coefficient when pitch angle is changed in accordance with a sinusoidal law. The results from DS model are in good agreement with experimental data for NACA 4415 shown in [7]. The waveform is defined by equation (32), as follows

$$
\alpha=\alpha_{0}+\Delta \alpha \sin (2 \pi f t)
$$

where initial AOA $\alpha_{0}=8^{\circ}, 14^{\circ}$ or $20^{\circ}$; $\Delta \alpha=10^{\circ}$; frequency $f=0.61 \mathrm{~Hz}$.

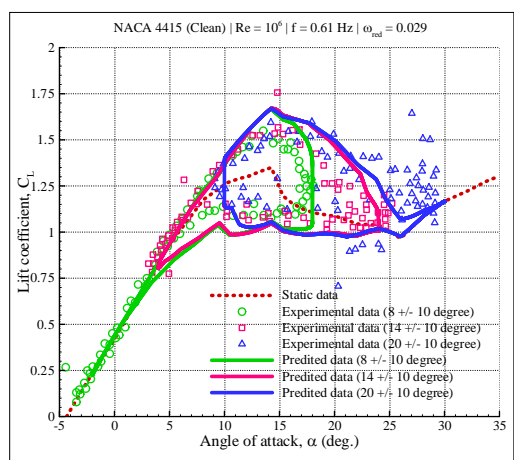

Figure 3. Dynamic lift coefficient of pitch oscillating

Table 2. Validation case tests

\begin{tabular}{|c|c|c|}
\hline & $\begin{array}{c}\text { SANDIA 17-m } \\
{[8,9]}\end{array}$ & $\begin{array}{c}\text { SANDIA 5-m } \\
{[10]}\end{array}$ \\
\hline $\begin{array}{c}\text { Rotor } \\
\text { geometry }\end{array}$ & Sandia & Troposkien \\
\hline Blades & $2 \times$ NACA 0015 & $2 \times$ NACA 0015 \\
\hline$C(\mathrm{~m})$ & 0.6096 & 0.1524 \\
\hline$H(\mathrm{~m})$ & 17 & 5.1 \\
\hline$R(\mathrm{~m})$ & 8.36 & 2.5 \\
\hline$\omega(\mathrm{rpm})$ & $38.7,42.2$ & 162.5 \\
\hline$\sigma$ & 0.16 & 0.15 \\
\hline
\end{tabular}

\section{Trang 58}


First attempt is made to validate the HKVAWT code by considering the intermediate results of the normal and tangential force coefficients at the equator of the rotor. The test data is provided for Darrieus VAWT SANDIA of height 17-m which was operated at a TSR of 3.09 and rotational speed of $38.7 \mathrm{rpm}$ [9]. Figure 4 compares experimental values of $C_{N}$ and $C_{T}$ [9] to those calculated by Eduard Dyachuk's work [8] of which DMST is employed and by the current HK-VAWT code. In addition, the AOA at the equator calculated by HK-VAWT is plotted versus azimuthal angle. It is visible from the graph that HK-VAWT's and Eduard Dyachuk's results are approximately matched at almost azimuthal angles regarding the $C_{N}$ and $C_{T}$ curves. It can be seen that the normal force coefficient $C_{N}$ calculated by the DMST method both in Eduard Dyachuk's work [8] and code HK-VAWT have the similar curve as a function of azimuthal angle compared with experimental $C_{N}$ [9]. However, discrepancy of $C_{N}$ values can be observed at some azimuthal positions. This fact can be explained by different values of stall AOA among experimental data and those from HK-VAWT with or without DS modeling. From Figure 4, the absolute stall AOA are determined respectively $7^{\circ}, 12^{\circ}$ and $9^{\circ}$ where sudden reduction in the absolute value of the normal force coefficient $C_{N}$ (represented and accounted for lift coefficients) appeared. However, the experimental results were discussed by Akins [9] as a default on measurement methods due to the response of pressure sensors. To sum up, the investigation of intermediate force coefficients between DMST methods (HK-VAWT's and Eduard Dyachuk's results) and experiment $[8,9]$ shows reasonable variation range and curve trend in the evolution of $C_{N}, C_{T}$ with azimuthal angles.

SANDIA $17-\mathrm{m}$ is also tested at another operating rotational speed of $42.2 \mathrm{rpm}$ [1]. Figure 5 compares experimental power coefficient to results from HK-VAWT (with and without DS modeling) and that of Paraschivoiu [1] (after applying Berg's DS model). Good agreement can be initially observed in the $\boldsymbol{C}_{\boldsymbol{P}}$ curves between experimental and analytical DMST approaches. It is shown that the DS model is implemented its task in a correct manner as the resulted power coefficient is closely coincided with the other two curves in the range of low TSR. Although slight differences can be detected from DMST calculation with and without DS effect in this test, the using of DS reduces the maximum power coefficient to 0.4 , which is quite closed to experiment, approximately at the same TSR between 5.5 and 6 .

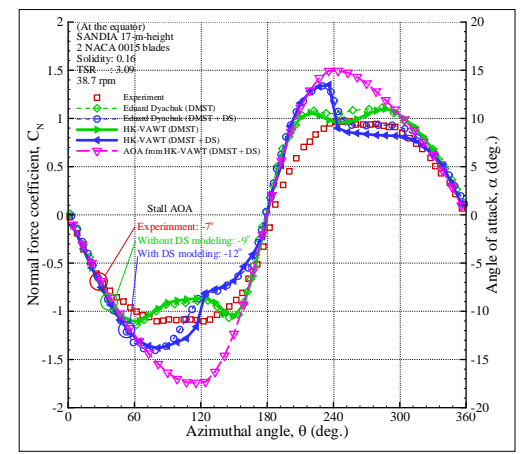

Figure 4. Normal force coefficient at the equator of SANDIA 17-m

The effect of the DS can be observed more clearly in Figure 6, which simulates the output power of SANDIA 5-m. The power coefficient increases at TSR varying from 1 to 4 , reaches the maximum at TSR from 4 to 8 and then decreases at higher TSR. Results given by HK-VAWT code are in good agreement with experimental ones especially in low TSR. In addition, when comparing to without DS modeling, HK-VAWT code with DS modeling slightly gives the better results at the low TSR. However, the difference in $\mathbf{C}_{\mathbf{P}}$ values suggests that the HK-VAWT code without or with DS model is incapable of predicting exactly the VAWT performance in the high TSR. 


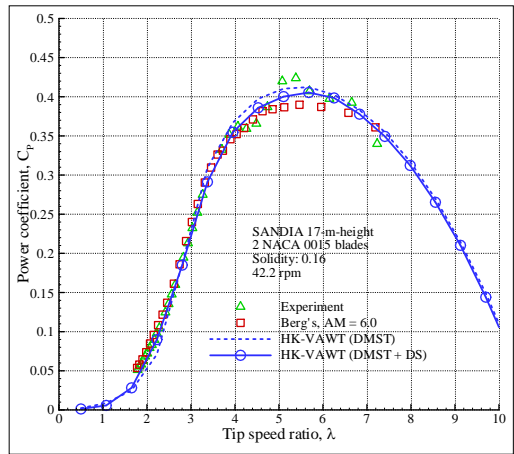

Figure 5. Power coefficient of SANDIA 17-m

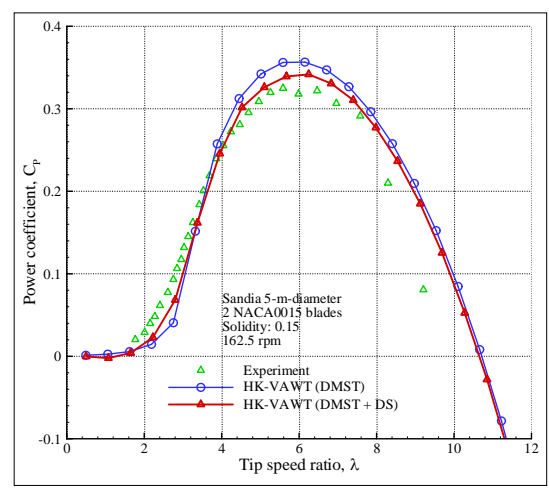

Figure 6. Power coefficient of SANDIA 5-m

\section{CONCLUSION}

This paper presents the methodology of an aerodynamic model for VAWT power estimation using DMST model and DS model. An analytical tool is built to compute automatically the power produced by Darrieus VAWTs with an available airfoils and rotor geometry data. The tool is also validated with experimental data. The results illustrate that it gives a good agreement with experimental data. The current HK-VAWT program only gives the good prediction for power coefficient at low and medium TSR range for VAWTs with curve blades. In order to account for unsteady aerodynamic aspects of flow around wind turbines blades, the code HK-VAWT should be integrated with models for stream-tube expansion, secondary effects, tip loss... to improve the predicting ability for all range of operating TSR and other types of vertical axis wind turbine. In conclusion, the HK-VAWT program is a useful tool in the design process of Darrieus VAWTs, which provides the rotor geometry with optimum power efficiency based on the wind potential of the installation site.

Acknowledgement: The authors would like thank to the Research Fund of Ho Chi Minh City University of Technology for its financial support to the research project T-KTGT-2015-42.

\section{Tính toán đáp ứng công suất của tua- bin gió trục đứng bằng lý thuyết đa ống dòng kép}

- Lê Thị Hồng Hiếu

- Nguyễn Chí Công

- Lương Hũu Trọng

Trường Đại học Bách Khoa, ĐHQG-HCM 


\section{TÓM TÁT}

Tua-bin gió có hai loại phổ biến là trục ngang và trục đứng được chế tạo để lấy năng lượng từ gió. Tua-bin gió loại trục đứng có một số ưu điểm so với loại trục ngang. Tuy vậy, do các hiện tượng khí động lực học phức tạp khi vận hành, việc tính toán đáp ứng công suất của tua-bin gió cần được nghiên cứu. Bài báo trình bày chương trình để tính toán đáp ứng của tua-bin gió trục đứng dựa trên cơ sở của lý thuyết đa ống dòng kép và hiệu chỉnh ảnh hưởng của hiện

Từ khóa: lý thuyết đa ống dòng kép DMST, tuabin gió trục đứng loại cánh cong Darrieus, chương trình HK-VAW, lý thuyết động lượng thẳng, lý thuyết phần tử cánh, hiện tượng mất lực nâng động trên cánh.

\section{REFERENCES}

[1]. I. Paraschivoiu, Wind Turbine Design with Emphasis Darrieus Concept. Canada, 2002.

[2]. IOPARA Inc., "CARDAAV - Comparison with Experimental and CFD Results."

[3]. Erich Hau. (2005). Wind turbines Fundamentals, Technologies, Application, Economics (2 ed.).

[4]. Nguyễn Văn Trọng, "Self-starting capability of Vertical axis wind turbine using DMST," Bachelor, Ho Chi Minh City University of Technology, 2012.

[5]. Robert E. Sheidahi and Paul C. Klimas, "Aerodynamic Characteristics of Seven Symmetrical Airfoil Sections Through 180Degree Angle of Attack for Use in Aerodynamic Analysis of Vertical Axis Wind Turbines," 1981.

[6]. [Christian Masson, Christophe Leclerc, and Ion Paraschivoiu, "Appropriate Dynamic- tượng mất lực nâng động. Chương trình giải thuật cho kết quả hệ số công suất của tuabin gió trục đứng ở các điều kiện hoạt động khác nhau đặc trưng bởi tỉ số vận tốc mũi. Các kết quả từ chương trình đã được kiểm chứng về độ tin cậy thông qua đối chiếu với các kết quả thực nghiệm được công bố của tua-bin loại cánh cong Darrieus của SANDIA.
Stall Models for Performance Predictions of VAWTs with NLF Blades," 1997.

[7]. M. J. Hoffmann, R. Reuss Ramsay, and G.M. Gregorek, "Effects of Grit Roughness and Pitch Oscillations on the NACA 4415 Airfoil," 1996.

[8]. Eduard Dyachuk and Anders Goude, "Simulating Dynamic Stall Effects for Vertical Axis Wind Turbines Applying a Double Multiple Streamtube Model," 2015.

[9]. R. E. Akins, "Measurements of Surface Pressures on an Operating Vertical-Axis Wind Turbine," 1989.

[10].Robert E.Sheldahl, Paul C.Klimas, and Louis V.Felts, "Aerodynamic performance of a 5-meter-diameter Darrieus turbine with extruded alumium NACA-0015 blades," 1980. 